\title{
Cost utility, budget impact, and scenario analysis of racecadotril in addition to oral rehydration for acute diarrhea in children in Malaysia
}

This article was published in the following Dove Press journal:

ClinicoEconomics and Outcomes Research

\author{
Tamlyn Anne Rautenberg ${ }^{1,2}$ \\ Ute Zerwes ${ }^{3}$ \\ Way Seah Lee ${ }^{4}$ \\ 'IGES Institut GmbH, Berlin, Germany; \\ ${ }^{2}$ Health Economics and HIVIAIDS \\ Research Division (HEARD), \\ University of KwaZulu-Natal, \\ Durban, KwaZulu-Natal, South Africa; \\ ${ }^{3}$ Assessment in Medicine $\mathrm{GmbH}$, \\ Lörrach, Germany; ${ }^{4}$ Department of \\ Pediatrics, University Malaya, Kuala \\ Lumpur, Malaysia
}

Objective: To perform cost utility (CU) and budget impact (BI) analyses augmented by scenario analyses of critical model structure components to evaluate racecadotril as adjuvant to oral rehydration solution (ORS) for children under 5 years with acute diarrhea in Malaysia.

Methods: A CU model was adapted to evaluate racecadotril plus ORS vs ORS alone for acute diarrhea in children younger than 5 years from a Malaysian public payer's perspective. A bespoke $\mathrm{BI}$ analysis was undertaken in addition to detailed scenario analyses with respect to critical model structure components.

Results: According to the CU model, the intervention is less costly and more effective than comparator for the base case with a dominant incremental cost-effectiveness ratio of -RM 1,272,833/quality-adjusted life year (USD -312,726/quality-adjusted life year) in favor of the intervention. According to the BI analysis (assuming an increase of 5\% market share per year for racecadotril+ORS for 5 years), the total cumulative incremental percentage reduction in health care expenditure for diarrhea in children is $0.136578 \%$, resulting in a total potential cumulative cost savings of -RM 73,193,603 (USD -17,983,595) over a 5-year period. Results hold true across a range of plausible scenarios focused on critical model components.

Conclusion: Adjuvant racecadotril vs ORS alone is potentially cost-effective from a Malaysian public payer perspective subject to the assumptions and limitations of the model. BI analysis shows that this translates into potential cost savings for the Malaysian public health care system. Results hold true at evidence-based base case values and over a range of alternate scenarios. Keywords: cost-effectiveness, cost utility, scenario analysis, budget impact, acute diarrhea

\section{Introduction}

Diarrheal disease is a leading cause of death in children under 5 years of age, and it is responsible for approximately 760,000 deaths in children every year. ${ }^{1}$ In Malaysia, it was estimated that there were 1,513,000 acute gastroenteritis (AGE)-related episodes of acute diarrhea (AD) per year, resulting in 234,000 outpatient visits, 70,000 hospitalizations, and 61 deaths in under-fives annually. ${ }^{2}$ According to the Malaysian Guidelines on the Management of Acute Diarrhea in Children, oral rehydration is recommended as first-line therapy for the management of children with $\mathrm{AD} .{ }^{3}$ Oral rehydration generally refers to rehydration by mouth, which may be by "custom-made" oral rehydration salt solution such as that recommended by the World Health Organization or a commercially available oral rehydration solution (ORS). Oral rehydration is an important measure for the treatment of diarrhea with dehydration but has no proven impact on the duration and severity of diarrhea.
Correspondence: Tamlyn Anne Rautenberg

IGES Institut $\mathrm{GmbH}$, Friedrichstraße 180, D-I0II7 Berlin, Germany

Tel +4930 277| I771881

Email rautenbergt@ukzn.ac.za 
Racecadotril is an antisecretory agent with a unique mechanism of action distinguishing it from other antidiarrheal agents. Racecadotril "decreases the intestinal hypersecretion of water and electrolytes induced by the cholera toxin or inflammation, and does not have effects on basal secretory activity. Racecadotril exerts rapid antidiarrhoeal action, without modifying the duration of intestinal transit." ${ }^{\prime 4}$ The safety profile,${ }^{5}$ clinical efficacy, ${ }^{6-13}$ and synthesis of efficacy ${ }^{14,15}$ have been previously described. Racecadotril has been commercially available in Malaysia since January 2014 and is currently not included on the National Formulary. In Malaysia, racecadotril is licensed as "complementary symptomatic treatment of acute diarrhoea in infants (older than 3 months) and in children together with oral rehydration and the usual support measures, when these measures alone are insufficient to control the clinical condition, and when causal treatment is not possible." ${ }^{4}$ According to the Malaysian Guidelines on the Management of Acute Diarrhea in Children, racecadotril may be considered as adjunctive therapy to ORS.

A previous cost utility (CU) study evaluated the use of racecadotril in a developed country setting. ${ }^{16}$ The same model was adapted for similar purpose in Thailand. ${ }^{17}$ However, to date, no studies have evaluated the $\mathrm{CU}$ of racecadotril in Malaysia; therefore, the objective of this analysis was to evaluate the $\mathrm{CU}$ of racecadotril in the context of Malaysia. The budget impact (BI) of adopting racecadotril+ORS ( $\mathrm{R}+\mathrm{ORS})$ was evaluated in the context of Malaysia. In addition, extensive scenario analyses were undertaken exploring a range of input scenarios and results with respect to critical components of the model to aid decision-making processes. Publicly available secondary data sources were used to carry out this research, and therefore ethics clearance was not required.

\section{Methods}

The original CU model Racecadotril for Acute Watery Diarrhea (RAWD) was the basis for a previous adaptation for Thailand and the current adaptation to Malaysia presented in this paper. ${ }^{16,17}$ The original CU model and the subsequent adaptation to Thailand have been described in detail. ${ }^{16,17}$ Briefly, the Excel-based CU analysis evaluates R+ORS vs ORS alone in children under 5 years with AD, over a 6 day time horizon, from a Malaysian public payer perspective. The comparator in the model is ORS alone, which is the standard of care recommended in the Malaysian Guidelines on the Management of Acute Diarrhea in children and in the context of this research refers to commercially available ORS. Results are presented as cost per quality-adjusted life years (QALYs).
Children in Malaysia with AD presented to an outpatient department at a public hospital. Standard of care is assumed to be first-line ORS given within the first 24 hours of diarrhea onset (T0-T24), as per the Malaysian clinical guideline. ${ }^{3}$

The CU model assumes that if the diarrhea resolves, no action is taken. If the diarrhea failed to resolve, then the child will have a follow-up visit to the public hospital outpatient department within 48 hours of treatment start $(\mathrm{T} 24<\mathrm{T} 72)$. At this point, it is assumed that children who are clinically dehydrated will be referred for public hospital inpatient admission (T72) and those without dehydration will continue treatment as before $(\leq \mathrm{T} 144)$. This assumption seems reasonable based on evidence for AGE that showed that the median duration of symptoms prior to admission in Malaysia was 2 days. ${ }^{18}$ The R+ORS pathway follows the same assumptions as the standard of care pathway except for the addition of adjuvant racecadotril.

Clinical efficacy, adverse event frequency, and utility data remained the same in the CU model adaptation and are elaborated further in the "Discussion" section. ${ }^{16}$ Cost data (and year of data) from sources in Malaysia were as follows: racecadotril cost per sachet RM 2.50 (2016), ${ }^{19}$ weighted average cost per sachet of five ORS brands in Malaysia RM 0.26 (2016), average cost per public hospital outpatient visit (USD61) (normal hours) RM 260 (2015), ${ }^{2}$ cost per public hospital bed/day (USD300) RM 1,280 (2015), ${ }^{2}$ cost of an episode of vomiting, fever, or allergic adverse events RM 20.00 (2016), respectively. All other CU model assumptions have been previously described and remain unchanged. ${ }^{16,17}$

Previous experience with the model has shown that there are two "critical components" of the CU model which are determined by the decision tree structure of the model and which potentially influence the model results as illustrated in Figure 1.

These critical components provide the rationale for the scenario analysis which was undertaken to evaluate the impact of changing the parameters in these critical components. The first critical component is that R+ORS affects diarrhea duration (the clinical evidence supports that there is a benefit $)^{14}$ and the model assumption that this directly impacts the number of follow-up outpatient visits. Diarrhea duration drives the number of follow-up outpatient visits, which in turn drives the difference in cost at 48 hours. For CU scenario 1 , we therefore conservatively estimated that R+ORS has a $10 \%$ favorable benefit over ORS alone (ie, 30/100 and 40/100 diarrhea resolves at 48 hours in the ORS alone and $\mathrm{R}+\mathrm{ORS}$ arms, respectively) and that all other parameters remain constant. The second critical component of the model 


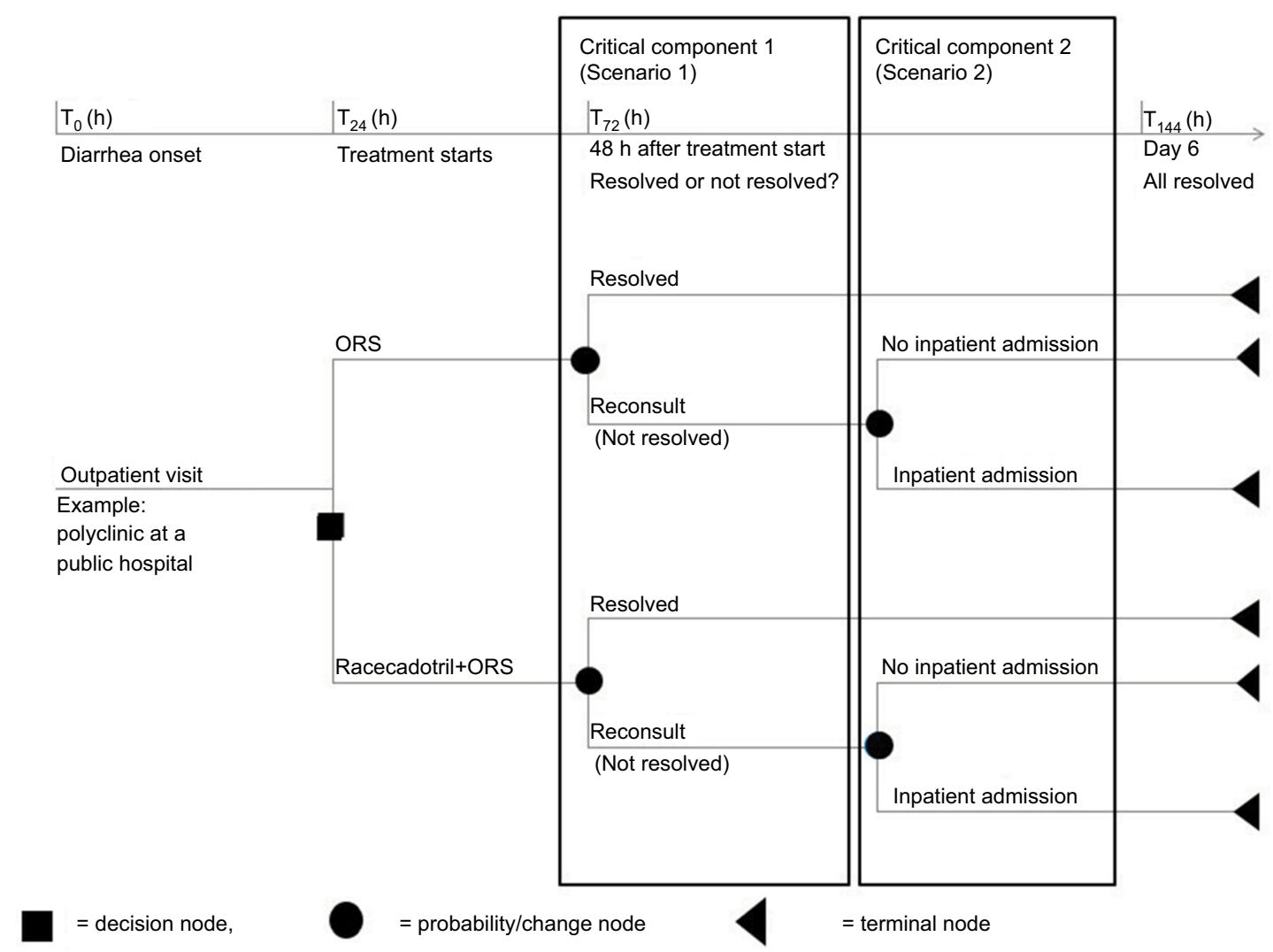

Figure I Critical model components driving the $\mathrm{CU}$ results of R+ORS vs ORS alone.

Abbreviations: $\mathrm{CU}$, cost utility; h, hours; ORS, oral rehydration solution; R+ORS, racecadotril+ORS; T, time.

relates to clinical dehydration status at follow-up outpatient visit and resultant hospital inpatient referral; therefore, $\mathrm{CU}$ analysis scenario 2 evaluates the change in results when the proportion of children referred for inpatient stay is varied. Therefore for CU scenario 2, it was conservatively and arbitrarily assumed that (compared to base case) fewer children in the ORS arm (36\% decreased to $30 \%$ ) and more children in the R+ORS arm (6\% increased to $20 \%)$ are referred for inpatient stay. Since the parameters in CU scenario 1 and $\mathrm{CU}$ scenario 2 are correlated, a third CU scenario was explored to evaluate the dual effect of altering both sets of parameters in CU scenario 1 and 2 simultaneously.

To evaluate the BI of adopting racecadotril in Malaysia, a bespoke BI model was programmed in Microsoft Excel (Microsoft, Redmond, WA, USA). The estimated number of children treated for AD per year is based on the total population in Malaysia $(30,331,000),{ }^{20}$ total number of children under 5 years $(2,477,000),{ }^{20}$ percentage of episodes of $\mathrm{AD}$ annually in under-fives $(59.47 \% \approx 1,473,072),{ }^{2}$ and the proportion of episodes of $\mathrm{AD}$ in children under five for whom treatment is sought $(20.1 \% \approx 295,940){ }^{2}$ This target population of 295,940 children under five eligible for treatment was evaluated in the BI calculation. Market share for R+ORS was assumed to increase by $5 \%$ every year for the 5 year BI analysis with ORS alone being replaced by $5 \%$, respectively, for each year. BI scenario analysis was undertaken varying the proportion of episodes for which medical treatment is sought. For BI scenario analysis, the base case value of $20.1 \%$ was varied to $16.1 \%$ and $24.1 \%$ for BI scenario 1 and 2 , respectively. In a final step, BI scenario 1 and BI scenario 2 were combined with $\mathrm{CU}$ scenario $1, \mathrm{CU}$ scenario 2 , and CU scenario 3 .

\section{Results}

The CU model base case analysis R+ORS vs ORS alone calculates the average cost savings per child at -RM 989 for an average gain of 0.0008 QALYs. The upfront increase in drug cost for R+ORS per child (+RM 15.73) is offset by savings due to reduction in outpatient (-RM 83.20), inpatient (-RM 921.75), and adverse event (-RM 0.08) costs, which results in a total net potential savings of -RM 989 per child per diarrhea episode in Malaysia. The incremental cost-effectiveness ratio (ICER) is - RM 1,272,833/QALY (USD -312,726/QALY), and the ICER 
for R+ORS is dominant over ORS alone. Therefore according to the CU model, R+ORS is less costly and more effective than ORS alone. The sensitivity of the CU model has been described extensively and applies again to this adaptation for Malaysia since the intrinsic model structure has remained unchanged. ${ }^{16,17}$ The $\mathrm{CU}$ base case analysis parameters and the corresponding cost-effectiveness results are shown in Figure 2.

CU scenario analysis 1 results showed that $\mathrm{R}+\mathrm{ORS}$ remained dominant over the comparator at -RM 2,185,152/ QALY (USD -536,890/QALY) as shown in Figure 3.

CU scenario analysis 2 showed that R+ORS remained dominant over the comparator at -RM 884,690/QALY as shown in Figure 4.

For scenario 3, the intervention remained dominant over the comparator at -RM 1,375,789/QALY (USD -338,030/ QALY) as shown in Figure 5.

The BI model base case shows that over a 5-year period (assuming that $20.1 \%{ }^{2}$ of children seek medical treatment), an increase of $5 \%$ in market share of $\mathrm{R}+\mathrm{ORS}$ over 5 consecutive years means a cumulative incremental reduction in the total health care budget of $0.136578 \%$, resulting in a total potential cost savings of-RM 73,193,603 (USD -17,983,595/QALY) over a 5 year period. The year on year percentage reduction in health care spend on childhood diarrhea is illustrated in Figure S1.

All combinations of BI and CU scenarios demonstrated a cumulative potential cost savings in the range of - RM 21,018,787 (USD -5,164,295) and -RM 87,803,178 (USD $-21,573,153)$, the "worst"- and "best"-case scenarios, respectively. All results are shown in Table 1.

\section{Discussion}

The limitations of the model have been extensively described. ${ }^{16,17}$ In short, wastage, compliance, and direct nonmedical and indirect medical costs are excluded from the model. The dose of racecadotril is based on the average weight of children under 5 years in Malaysia, which was estimated at $10.9 \mathrm{~kg},{ }^{21}$ and due to the roundup of drug sachets the base case results hold true for weight range $6.7 \leq 13.3 \mathrm{~kg}$. The clinical data used for the adaptation of the model and the rationale have been previously explained. ${ }^{16,17}$

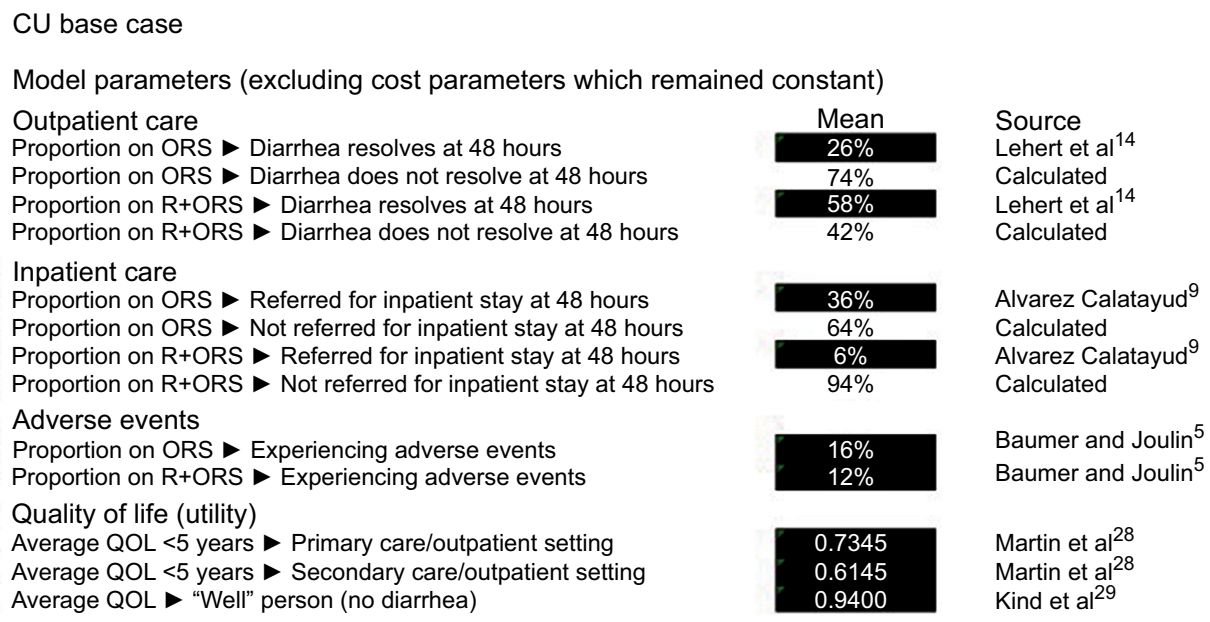

Source

Lehert et al $^{14}$

Calculated

Lehert et al $^{14}$

Calculated

Alvarez Calatayud $^{9}$

Calculated

Alvarez Calatayud $^{9}$

Calculated

Baumer and Joulin 5

Baumer and Joulin 5

Martin et $\mathrm{al}^{28}$

Martin et $\mathrm{al}^{28}$

Kind et $\mathrm{al}^{29}$

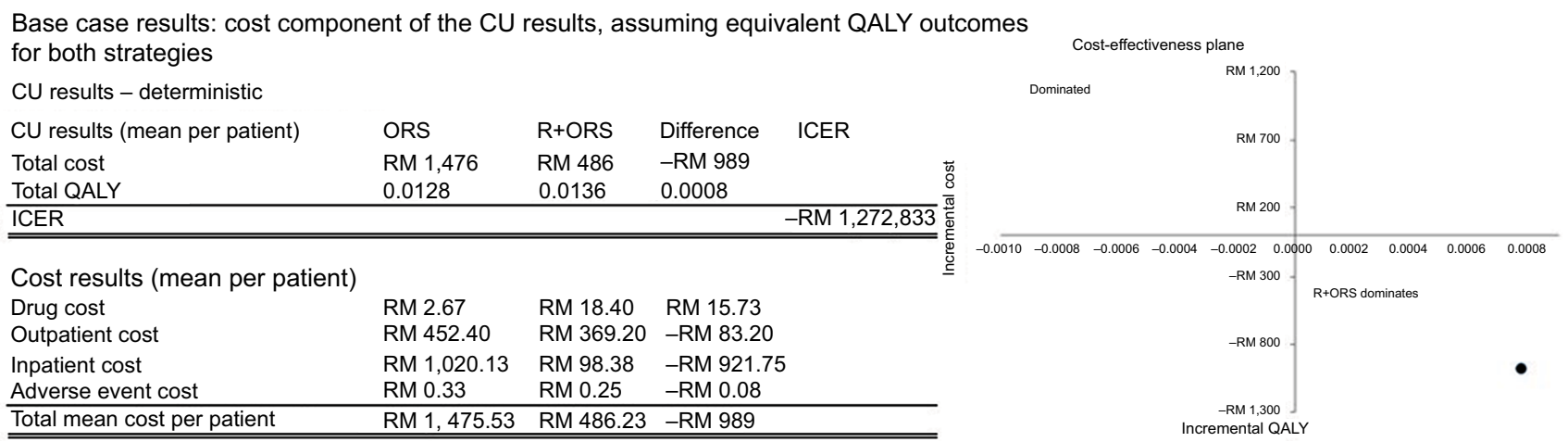

Figure $2 \mathrm{CU}$ model base case parameters and corresponding cost component of $\mathrm{CU}$ results.

Note: All parameters are shown except for cost parameters which remained constant at base case values.

Abbreviations: CU, cost utility; ICER, incremental cost-effectiveness ratio; ORS, oral rehydration solution; QALY, quality-adjusted life year; QOL, quality of life; R+ORS, racecadotril+ORS; RM, Malaysian Ringgit. 


\begin{tabular}{|c|c|c|c|}
\hline \multicolumn{4}{|c|}{ Model parameters (excluding cost parameters which remained constant) } \\
\hline Outpatient care & Mean & Source & \\
\hline 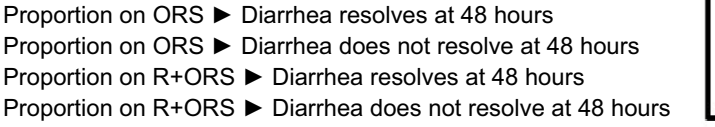 & $\begin{array}{l}30 \% \\
70 \% \\
60 \% \\
60 \% \\
\end{array}$ & $\begin{array}{l}\text { Scenario } 1 \text { analysis } \\
\text { Calculated } \\
\text { Scenario } 1 \text { analysis } \\
\text { Calculated }\end{array}$ & Scenario 1 \\
\hline $\begin{array}{l}\text { Inpatient care } \\
\text { Proportion on ORS }>\text { Referred for inpatient stay at } 48 \text { hours } \\
\text { Proportion on ORS }>\text { Not referred for inpatient stay at } 48 \text { hours } \\
\text { Proportion on R+ORS }- \text { Referred for inpatient stay at } 48 \text { hours } \\
\text { Proportion on R+ORS }>\text { Not referred for inpatient stay at } 48 \text { hours }\end{array}$ & $\begin{array}{c}36 \% \\
64 \% \\
6 \% \\
94 \%\end{array}$ & $\begin{array}{l}\text { Alvarez Calatayud }^{9} \\
\text { Calculated } \\
\text { Alvarez Calatayud }^{9} \\
\text { Calculated }\end{array}$ & \\
\hline $\begin{array}{l}\text { Adverse events } \\
\text { Proportion on ORS }>\text { Experiencing adverse events } \\
\text { Proportion on R+ORS }>\text { Experiencing adverse events }\end{array}$ & $\begin{array}{l}16 \% \\
12 \%\end{array}$ & $\begin{array}{l}\text { Baumer and Joulin } \\
\text { Baumer and Joulin }\end{array}$ & \\
\hline $\begin{array}{l}\text { Quality of life (utility) } \\
\text { Average QOL }<5 \text { years }>\text { Primary care/outpatient setting } \\
\text { Average QOL }<5 \text { years }>\text { Secondary care/outpatient setting } \\
\text { Average QOL }>\text { "Well" person (no diarrhea) }\end{array}$ & $\begin{array}{l}0.7345 \\
0.6145 \\
0.9400\end{array}$ & $\begin{array}{l}\text { Martin et } \mathrm{al}^{28} \\
\text { Martin et } \mathrm{al}^{28} \\
\text { Kind et } \mathrm{al}^{29}\end{array}$ & \\
\hline
\end{tabular}

Scenario 1 results: cost component of the CU results, assuming equivalent QALY outcomes for both strategies

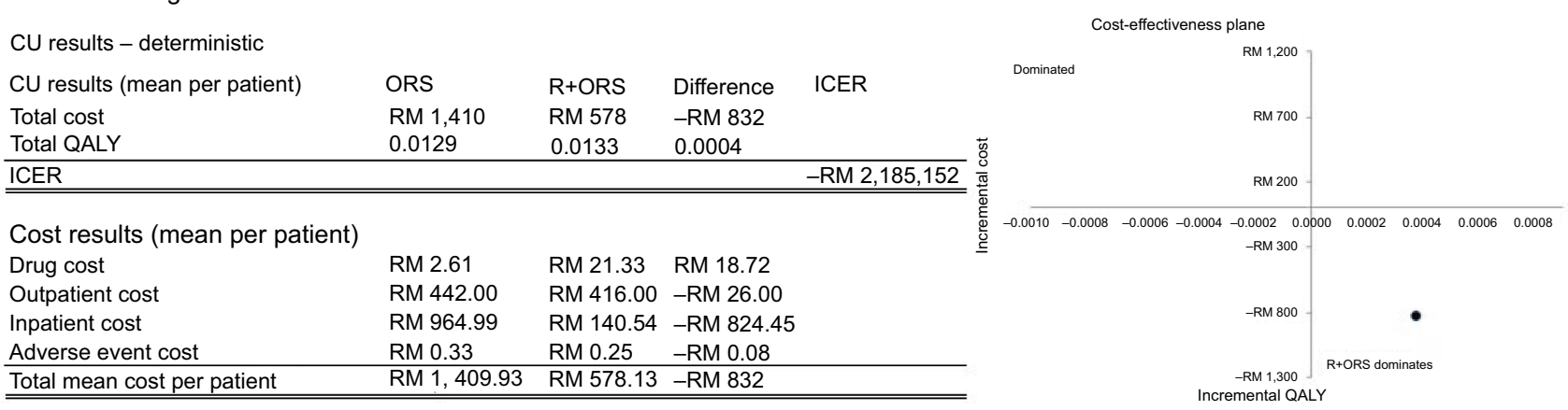

Figure $3 \mathrm{CU}$ model scenario I parameters and corresponding cost component of CU results.

Note: All parameters are shown except for cost parameters which remained constant at base case values.

Abbreviations: CU, cot utility; ICER, incremental cost-effectiveness ratio; ORS, oral rehydration solution; QALY, quality-adjusted life year; QOL, quality of life; R+ORS, racecadotril+ORS; RM, Malaysian Ringgit.

The extensive use of scenario analysis can contribute to the decision-making process regarding the adoption of racecadotril into the National Formulary in Malaysia. To further illustrate the impact of the critical components of the CU model on the results, let us assume that we have a cohort of 100 children with AD. The Lehert meta-analysis reported a hazard ratio in favor of R+ORS of 2.04 (95\% CI: $1.85-2.32 ; p<0.001) .{ }^{14}$ By fitting a Weibull distribution to the data and applying a proportional hazards assumption, ${ }^{16}$ we see that within 48 hours diarrhea will resolve in 26 of 100 children who have standard of care (ORS alone), but in the remainder of children (74 of 100) diarrhea will not resolve. ${ }^{16}$ In comparison, for R+ORS diarrhea will resolve in 58 of 100 children and will not resolve in the remainder of children (42 of 100). ${ }^{16}$ It follows that if there are fewer children with diarrhea at 48 hours from treatment start, then fewer children will probably present for a follow-up visit to an outpatient department for persistently AD. In the model, it is assumed that this number of children with $\mathrm{AD}$ at 48 hours directly corresponds to the number of children who revisit an outpatient facility. Therefore, diarrhea duration drives the number of follow-up outpatient visits, which in turn drives the difference in cost at 48 hours. The decision-maker needs to decide on the strength of this estimate of effect for Malaysia, considering the internal and external validity of the clinical studies, the quality of the meta-analysis, etc. If there is reason to believe that this effect would be greater (potentially due to the incidence of comorbidities) or lesser (potentially due to difficulty in administering the drug in timely manner), then we consider CU scenario 1 analysis, which evaluates a change in results when the proportion of children whose diarrhea resolves within 48 hours is varied for both arms. It was conservatively and arbitrarily assumed that (compared to base case) more children on ORS ( $26 \%$ increased to $30 \%$ ) resolved and that fewer children on R+ORS ( $58 \%$ decreased to $40 \%$ ) resolved at 48 hours. Therefore, in the worst-case CU scenario 1, (lowering the relative efficacy of R+ORS vs ORS alone) $\mathrm{R}+\mathrm{ORS}$ remains cost-effective with a dominant ICER. It is the combined effect of reduction in diarrhea duration which impacts the 
CU scenario 2

Model parameters (excluding cost parameters which remained constant)

\begin{tabular}{|c|c|c|c|}
\hline Outpatient care & Mean & Source & \\
\hline Proportion on ORS Diarrhea resolves at 48 hours & $26 \%$ & Lehert et al $^{14}$ & \\
\hline Proportion on ORS Diarrhea does not resolve at 48 hours & $74 \%$ & Calculated & \\
\hline Proportion on R+ORS Diarrhea resolves at 48 hours & $58 \%$ & Lehert et $\mathrm{al}^{14}$ & \\
\hline Proportion on R+ORS Diarrhea does not resolve at 48 hours & $42 \%$ & Calculated & \\
\hline \multicolumn{4}{|l|}{ Inpatient care } \\
\hline Proportion on ORS Referred for inpatient stay at 48 hours & $30 \%$ & Scenario 2 analysis & \\
\hline Proportion on ORS Not referred for inpatient stay at 48 hours & $70 \%$ & Calculated & \\
\hline Proportion on R+ORS - Referred for inpatient stay at 48 hours & $20 \%$ & Scenario 2 analysis & \\
\hline Proportion on R+ORS - Not referred for inpatient stay at 48 hour & $80 \%$ & Calculated & Scenario 2 \\
\hline \multicolumn{4}{|l|}{ Adverse events } \\
\hline Proportion on ORS - Experiencing adverse events & $16 \%$ & Baumer and Joulin ${ }^{5}$ & \\
\hline Proportion on $\mathrm{R}+\mathrm{ORS} \triangleright$ Experiencing adverse events & $12 \%$ & Baumer and Joulin ${ }^{5}$ & \\
\hline \multicolumn{4}{|l|}{ Quality of life (utility) } \\
\hline Average $\mathrm{QOL}<5$ years $>$ Primary care/outpatient setting & 0.7345 & Martin et $\mathrm{al}^{28}$ & \\
\hline Average QOL $<5$ years $>$ Secondary care/outpatient setting & 0.6145 & Martin et $\mathrm{al}^{28}$ & \\
\hline Average QOL "Well" person (no diarrhea) & 0.9400 & Kind et $\mathrm{al}^{29}$ & \\
\hline
\end{tabular}

Scenario 2 results: cost component of the CU results, assuming equivalent QALY outcomes for both strategies

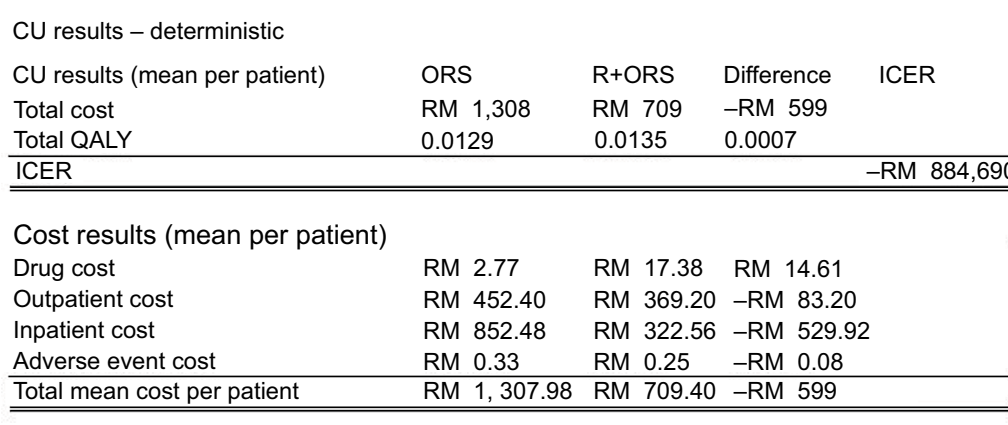

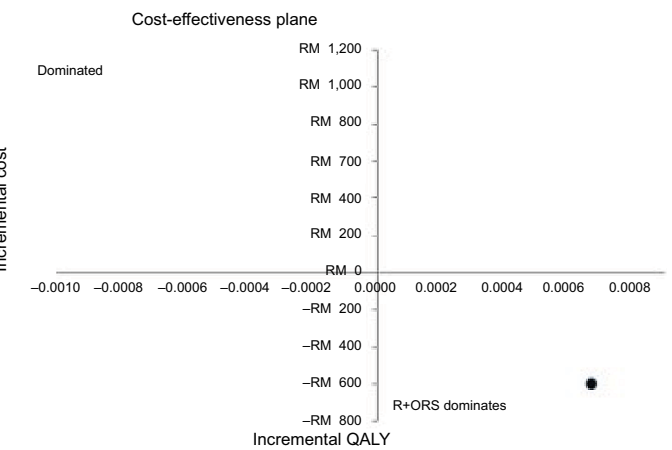

Figure $4 \mathrm{CU}$ model scenario 2 parameters and corresponding cost component of $\mathrm{CU}$ results.

Note: All parameters are shown except for cost parameters which remained constant at base case values.

Abbreviations: CU, cost utility; ICER, incremental cost-effectiveness ratio; ORS, oral rehydration solution; QALY, quality-adjusted life year; QOL, quality of life; R+ORS, racecadotril+ORS; RM, Malaysian Ringgit.

number of repeat outpatient visits that results in a cost benefit. From a Malaysian public payer perspective then, if there is sound reason to believe that this holds true, then there will be a reduction in follow-up outpatient visits and a resultant cost advantage for $\mathrm{R}+\mathrm{ORS}$. It is reported that in Malaysia there are an estimated 234,000 outpatient visits due to annual episodes of AGE; ${ }^{2}$ however, it is unclear what proportion are first and second visits.

For critical component 2, clinical study data from Spain demonstrates that the referral rate to inpatient care is $6.1 \%$ and $35.9 \%$ for R+ORS vs ORS alone respectively at 48 hours $(p<0.0001) .{ }^{9}$ This study approximately corresponds to Loganathan's ${ }^{2}$ report that there are 234,000 outpatient visits and 70,000 hospitalizations annually due to AGE such that if we assume that children who are hospitalized have been seen at an outpatient clinic at least once, then $29.9 \%$ of children seen in the outpatient setting in Malaysia are being referred to inpatient setting. Based on the study data in our cohort of 100 children, 36 of 100 children on ORS alone and 6 of 100 on R+ORS would be referred for inpatient stay. ${ }^{9}$ However if there is reason to believe that this is different, then we would explore $\mathrm{CU}$ scenario 2. Again, $\mathrm{R}+\mathrm{ORS}$ remains cost-effective due to the marginal difference in the number of children being referred for inpatient stay. Both CU scenario 1 and $\mathrm{CU}$ scenario 2 are useful to understand how the individual parameters affect the model results. However, these parameters are correlated; therefore, it is important to explore the combined effect of CU scenario 1 and CU scenario 2 in CU scenario 3. The results in Table 1 show that for a range of plausible scenarios these values result in a dominant ICER for R+ORS. It can be seen that it is the combined effect of reduction in diarrhea duration resulting in reduction of repeat outpatient visits combined with reduction in inpatient referrals which drive the favorable benefits for R+ORS. Assuming that one or other of these effects is null persistently results in a favorable result for R+ORS. For example, if there is no difference in diarrhea duration between R+ORS and ORS alone, the results remain favorable. Alternately, if there is no difference in 
CU scenario 3 (scenario 1 and 2 combined)

\begin{tabular}{|c|c|c|c|}
\hline \multicolumn{4}{|c|}{ Model parameters (excluding cost parameters which remained constant) } \\
\hline Outpatient care & Mean & \\
\hline Proportion on ORS D Diarrhea resolves at 48 hours & $30 \%$ & Scenario 1 analysis & \\
\hline Proportion on ORS $>$ Diarrhea does not resolve at 48 hours & $70 \%$ & Calculated & \\
\hline Proportion on $\mathrm{R}+\mathrm{ORS}$ Diarrhea resolves at 48 hours & $40 \%$ & Scenario 1 analysis & \\
\hline Proportion on R+ORS D Diarrhea does not resolve at 48 hours & $60 \%$ & Calculated & Scenario 1 \\
\hline \multicolumn{4}{|l|}{ Inpatient care } \\
\hline Proportion on ORS $>$ Referred for inpatient stay at 48 hours & $30 \%$ & Scenario 2 analysis & \\
\hline Proportion on ORS $\triangleright$ Not referred for inpatient stay at 48 hours & $70 \%$ & Calculated & \\
\hline Proportion on R+ORS $>$ Referred for inpatient stay at 48 hours & $20 \%$ & Scenario 2 analysis & \\
\hline Proportion on R+ORS $>$ Not referred for inpatient stay at 48 hours & $80 \%$ & Calculated & Scenario 2 \\
\hline \multicolumn{4}{|l|}{ Adverse events } \\
\hline Proportion on ORS $\$ Experiencing adverse events & $16 \%$ & Baumer and Joulin ${ }^{5}$ & \\
\hline Proportion on R+ORS $>$ Experiencing adverse events & $12 \%$ & Baumer and Joulin 5 & \\
\hline \multicolumn{4}{|l|}{ Quality of life (utility) } \\
\hline Average $\mathrm{QOL}<5$ years $>$ Primary care/outpatient setting & 0.7345 & Martin et al ${ }^{28}$ & \\
\hline Average $\mathrm{QOL}<5$ years $>$ Secondary care/outpatient setting & 0.6145 & Martin et $\mathrm{al}^{28}$ & \\
\hline Average QOL $\downarrow$ "Well" person (no diarrhea) & 0.9400 & Kind et al ${ }^{29}$ & \\
\hline
\end{tabular}

Scenario 3 results: cost component of the CU results, assuming equivalent QALY outcomes
for both strategies for both strategies

CU results - deterministic

CU results (mean per patient)

Total cost

Total QALY

ICER

Cost results (mean per patient)

\section{Drug cost}

Outpatient cost

Inpatient cost

Adverse event cost

Total mean cost per patient

\section{ORS R+ORS Difference ICER \\ RM 1,251 RM $897 \quad-$ RM 355 \\ $\begin{array}{lll}0.0129 & 0.0132 & 0.0003\end{array}$}

\begin{tabular}{lll} 
RM 2.71 & RM 19.88 & RM 17.18 \\
RM 442.00 & RM 416.00 & -RM 26.00 \\
RM 806.40 & RM 460.80 & -RM 345.60 \\
RM 0.33 & RM 0.25 & -RM 0.08 \\
RM 1,251.44 & RM 896.94 & -RM 355 \\
\hline
\end{tabular}

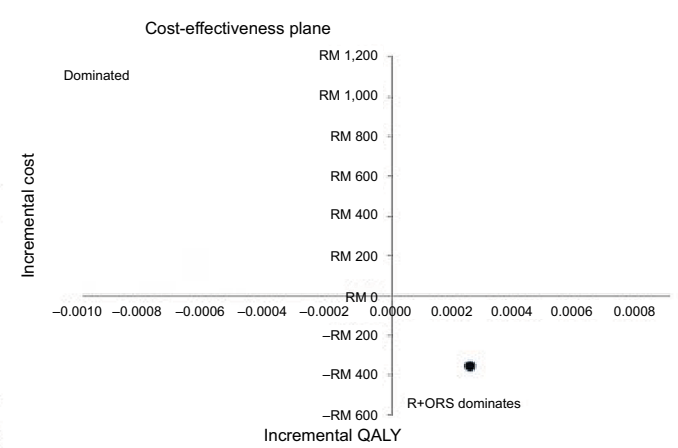

Figure $5 \mathrm{CU}$ model scenario 3 (CU scenario I and CU scenario 2 combined) parameters and corresponding cost component of CU results.

Note: All parameters are shown except for cost parameters which remained constant at base case values.

Abbreviations: CU, cost utility; ICER, incremental cost-effectiveness ratio; ORS, oral rehydration solution; QALY, quality-adjusted life year; QOL, quality of life; R+ORS, racecadotril+ORS; RM, Malaysian Ringgit.

inpatient referral for R+ORS vs ORS alone, then results are still favorable. These results are reassuring that in worse-case scenarios R+ORS appears to be cost-effective conditional upon a reduction in diarrhea duration (clinical benefit) and a reduction in inpatient referrals. Jointly, the results remain favorable as described in the scenario analysis earlier.

This analysis would benefit from real-world data characterizing the current rate of outpatient and inpatient visits between day 2 and 5 in children with $\mathrm{AD}$ in Malaysia in public health care facilities.

The Malaysian PE guidelines recommend CU analysis as the economic evaluation method of choice where the prescribed outcome is QALY, and this criterion has been satisfied in this analysis. ${ }^{22}$ However, as previously described, the model results are highly sensitive to the quality of life of a "well" person and a child with diarrhea in the inpatient and outpatient settings respectively. ${ }^{16,17}$ It is debatable whether the gain in QALY is meaningful to the child with diarrhea, and therefore to the Malaysian public payer. Therefore, if we assume no gain in QALY (equivalent QALY outcome but persistent benefit in reduction of duration of diarrhea) and undertake a cost minimization analysis, the average potential cost savings per child treated with R+ORS vs ORS alone remains -RM 989 and R+ORS remains cost saving conditional on a sustained reduction in follow-up outpatient visits (due to reduction in diarrheal duration) and a difference in inpatient referrals. The key to the decision for Malaysian public payers is therefore whether there is evidence to support the reduction in diarrheal duration, the resultant reduction in follow-up outpatient visits and inpatient referrals, and the magnitude of the difference in cost between public hospital inpatient and public hospital outpatient department care.

The greatest uncertainty in the BI calculation is presumed to arise from the annual incidence of the number of episodes of AGE per year in Malaysia, which is estimated at $59.47 \%^{2}$ and aligns with alternate evidence from Gurpreet ${ }^{23}$ which reports cumulative incidence of $4.5 \%$ over a 4 -week period, which is $1.125 \%$ per week and $58.5 \%$ per year (assuming no clear seasonality in Malaysia in line with the literature). ${ }^{24-27}$ According to the BI model, this results in a total of 1,473,072 episodes of AGE in children under 5 per year, which is aligned 
Table I BI and CU modeled sensitivity analysis scenarios and corresponding cumulative (5 year) $\mathrm{BI}$ results

\begin{tabular}{|c|c|c|}
\hline Modelled Scenario & $\begin{array}{l}\text { Cumulative (5 year) } \\
\text { BI Results (RM) }\end{array}$ & $\begin{array}{l}\text { Cumulative (5 year) } \\
\text { BI Results (USD) }\end{array}$ \\
\hline BI scenario $2(24.1 \%)+C U$ base case & $-\mathrm{RM} 87,803,178$ & -USD $21,573,153$ \\
\hline BI scenario 2 (24.1\%)+CU scenario I & -RM 73,824,988 & -USD $18,138,726$ \\
\hline BI base case $(20.1 \%)+$ CU base case ${ }^{a}$ & $-\mathrm{RM} 73,193,603^{\mathrm{a}}$ & -USD $17,983,595$ \\
\hline BI base case $(20.1 \%)+C U$ scenario I & $-R M 61,541,246$ & -USD $15,120,623$ \\
\hline BI scenario I $(16.1 \%)+\mathrm{CU}$ base case & -RM 58,656,895 & -USD $|4,4| I, 940$ \\
\hline BI scenario $2(24.1) / 0)+C U$ scenario 2 & -RM 53, I25,834 & -USD $13,052,964$ \\
\hline BI scenario I (I6.1\%)+CU scenario I & -RM 49,318,768 & -USD I2,117,572 \\
\hline BI base case $(20.1 \%)+C U$ scenario 2 & $-\mathrm{RM} 44,286,224$ & -USD I0,88I,08I \\
\hline BI scenario I (I6.1\%)+CU scenario 2 & -RM 35,490,703 & -USD 8,720,030 \\
\hline BI scenario $2(24.1 \%)+C U$ scenario 3 & -RM 31,462,904 & -USD 7,730,404 \\
\hline BI base case $(20.1 \%)+C U$ scenario 3 & -RM 26,240,846 & -USD 6,447,350 \\
\hline BI scenario I (16.1\%)+CU scenario 3 & $-R M 21,018,787$ & -USD 5, I64,295 \\
\hline
\end{tabular}

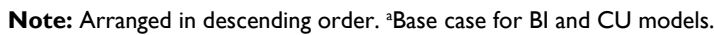

Abbreviations: Bl, budget impact; CU, cost utility; RM, Malaysian Ringgit.

to the $1,265,875$ episodes per year reported by Gurpreet et $\mathrm{al}^{23}$ and the 1,513,000 episodes of AGE reported by Loganathan et al. ${ }^{2}$ Therefore, these estimates seem reasonable. The second source of uncertainty in the BI calculation arises from the estimate of the proportion of children with $\mathrm{AD}$ for whom medical treatment will be sought which, according to the Loganathan study, ${ }^{2}$ is calculated to be $20.1 \%$ for the base case (all outpatient and hospitalizations as a percentage of all episodes). Although the evidence appears sound, exploring BI scenario 1 and BI scenario 2 alone and in combination with CU scenarios 1, 2, and 3 show that the potential for cost savings ranges from -RM 21,018,787 in the "worst"-case to -RM $87,803,178$ in the "best"-case scenarios.

\section{Conclusion}

Adjuvant racecadotril compared to ORS alone is potentially costeffective from a Malaysian public payer perspective, subject to the assumptions and limitations of the model. BI analysis shows that adopting $\mathrm{R}+\mathrm{ORS}$ translates into potential cost savings for the Malaysian public health care system at evidence-based base case values and over a range of alternate scenarios.

\section{Acknowledgments}

The authors thank Abbott affiliates in Malaysia for providing data for the model and Annette Gerritsen for review and verification of the epidemiological data and incidence of annual episodes of AD in children in Malaysia.

The analysis described in this manuscript was funded by Abbott Laboratories. TR, UZ, and LWS had the final decision regarding manuscript content.

\section{Disclosure}

The authors report no conflicts of interest in this work.

\section{References}

1. World Health Organization. Diarrhoeal Disease Fact Sheet 2013. Geneva, Switzerland: World Health Organization; 2013. Available from: http:// www.who.int/mediacentre/factsheets/fs330/en/. Accessed May 2016.

2. Loganathan $\mathrm{T}, \mathrm{Ng} \mathrm{CW}$, Lee WS, Jit M. The hidden health and economic burden of rotavirus gastroenteritis in Malaysia: an estimation using multiple data sources. Pediatr Infect Dis J. 2016;35(6):601-606.

3. Academy of Medicine of Malaysia. Guidelines on the management of acute diarrhoea in children 2011. Available from: http://acadmed. org. my/index.cfm?\&menuid=83\&parentid=34. Accessed April 2017.

4. National Pharmaceutical Control Bureau. Hidrasec children $30 \mathrm{mg}$ granules for oral suspension. Petaling Jaya, Malaysia: National Pharmaceutical Control Bureau; 2013.

5. Baumer P, Joulin Y. Pre- and postmarketing safety profiles of Racecadotril sachets, a "new" antidiarrhoeal drug. J Pediatr Gastroenterol Nutr. 2009;48(Suppl 3):E99.

6. Cezard JP, Duhamel JF, Meyer M, et al. Efficacy and tolerability of racecadotril in acute diarrhea in children. Gastroenterology. 2001;120(4):799-805.

7. Cojocaru B, Bocquet N, Timsit S, et al. Effect of racecadotril in the management of acute diarrhea in infants and children. Arch Pediatr. 2002;9(8): 774-779.

8. Santos M, Marañón R, Miguez C, Vázquez P, Sánchez C. Use of racecadotril as outpatient treatment for acute gastroenteritis: a prospective, randomized, parallel study. J Pediatr. 2009;155(1):62-67.

9. Alvarez Calatayud E, Pinei Simon G, Taboada Castro L, et al. Efectividad de racecadotrilo en el tratamiento de la gastroenteritis aguda [The effectiveness of racecadotril in the treatment of acute gastroenteritis]. Acta Pediatr Esp. 2009;67(3):117-122. Spanish.

10. Salazar-Lindo E, Santisteban-Ponce J, Chea-Woo E, Gutierrez M. Racecadotril in the treatment of acute watery diarrhea in children. $N$ Engl J Med. 2000;343(7):463-467.

11. Savita MR, Mysore GMC. Racecadotril - a novel drug for the treatment of acute watery diarrhea in Indian children; 2006. Available from: http:// www.pediatriconcall.com/fordoctor/conference_abstracts/racecadotrial. asp. Accessed December 1, 2014.

12. Gutierrez-Castrellon P, Acosta-Bastidas M, Llamosas Gallardo B, et al. Ensayo clinico aleatorizado y analisis farmacoeconomico del impacto de racecadotrilo (Hidrasec) como coadyuvante en el tratamiento de la gastroenetritis aguda sobre la reduccion de los gastos hospitalierios relacionados en lactantes menores de 24 meses en Mexico. [Randomized clinical trial and pharmacoeconomic analysis of the impact of racecadotril (Hidrasec $\AA$ ) as an adjuvant in the treatment of acute gastroenteritis on the reduction of hospital related expenses in infants under 24 months in Mexico]. Rev Invest Clin. In press 2011. Spanish. 
13. Melendez Garcia JM, Rodriguez JT. Racecadotril en el tratamiento de la diarrea agudo en ninos. [Racecadotril in the treatment of Acute diarrhea in children]. RevFacultad Med (Guatemala). 2007;4:25-28. Spanish.

14. Lehert P, Cheron G, Calatayud GA, et al. Racecadotril for childhood gastroenteritis: an individual patient data meta-analysis. Dig Liver Dis. 2011;43(9):707-713.

15. Gordon M, Akobeng A. Racecadotril for acute diarrhoea in children: systematic review and meta-analyses. Arch Dis Child. 2016;101(3): 234-240.

16. Rautenberg TA, Zerwes U, Foerster D, Aultman R. Evaluating the cost utility of racecadotril for the treatment of acute watery diarrhea in children: the RAWD model. Clinicoecon Outcomes Res. 2012;4: 109-116.

17. Rautenberg TA, Zerwes U. The cost utility and budget impact of adjuvant racecadotril for acute diarrhea in children in Thailand. Clinicoecon Outcomes Res. 2017;9:411-422.

18. Izzuddin Poo M, Lee WS. Admission to hospital with childhood acute gastroenteritis in Kuala Lumpur, Malaysia. Med J Malaysia. 2007;62(3):189-193.

19. Abbott Laboratories. Racecadotril Moving Annual Total Drug Cost, Fourth Quarter. Chicago, IL: Abbott Laboratories; 2016.

20. United Nations Department of Economic and Social Affairs. The world population prospects: 2015 revision; 2015 . Available from: http://www un.org/en/development/desa/publications/world-population-prospects2015-revision.html. Accessed May 2017.
21. Bong Y, Shariff AA, Mohamed AM, Merican AF. Malaysian growth centiles for children under six years old. Ann Hum Biol. 2015;42(2): $108-115$.

22. Ministry of Health Malaysia, Pharmaceutical Services Divisions. Pharmacoeconomic Guideline for Malaysia; 2012. Available from: http://www.pharmacy.gov.my/v2/en/documents/pharmacoeconomicguideline-malaysia.html. Accessed April 2017.

23. Gurpreet K, Tee GH, Amal NM, Paramesarvathy R, Karuthan C. Incidence and determinants of acute diarrhoea in Malaysia: a populationbased study. J Health Popul Nutr. 2011;29(2):103-112.

24. Lee WS, Veerasingam PD, Goh AY, Chua KB. Hospitalization of childhood rotavirus infection from Kuala Lumpur, Malaysia. J Paediatr Child Health. 2003;39(7):518-522.

25. Hsu VP, Abdul Rahman HB, Wong SL, et al. Estimates of the burden of rotavirus disease in Malaysia. J Infect Dis. 2005;192(Suppl 1):S80-S86.

26. Hung LC, Wong SL, Chan LG, Rosli R, Ng AN, Bresee JS. Epidemiology and strain characterization of rotavirus diarrhea in Malaysia. Int $J$ Infect Dis. 2006;10(6):470-474.

27. Patel MM, Pitzer VE, Alonso WJ, et al. Global seasonality of rotavirus disease. Pediatr Infect Dis J. 2013;32(4):e134-e147.

28. Martin A, Cottrell S, Standaert B. Estimating utility scores in young children with acute rotavirus gastroenteritis in the UK. J Med Econ. 2008;11(3):471-484.

29. Kind P, Hardman G, Macran S. UK population norms for EQ-5D. Discussion paper 172; 1999. Available from: https:/www.york.ac.uk/ che/pdf/DP172.pdf. Accessed June 9, 2017. 


\section{Supplementary material}

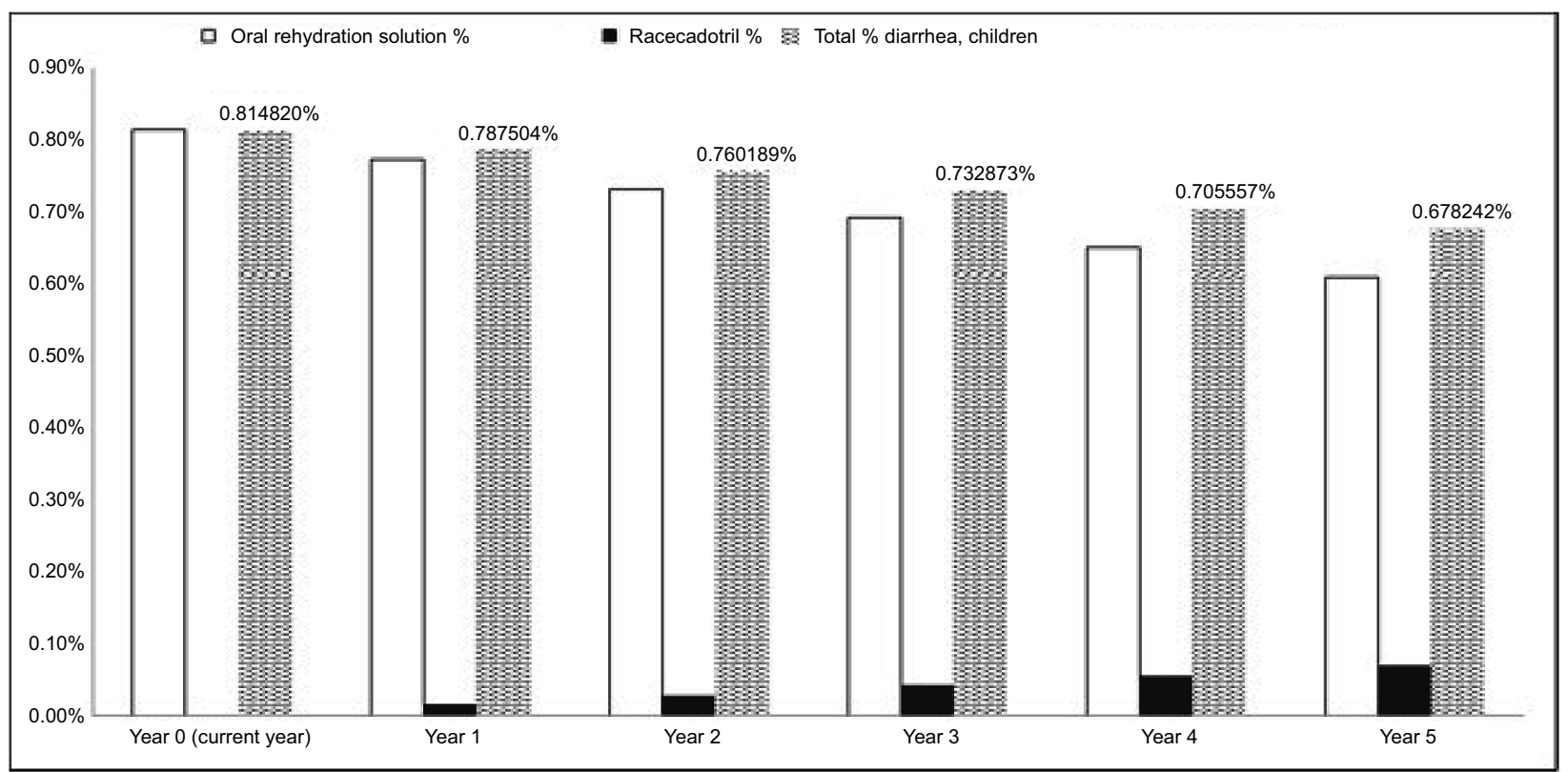

Figure SI Percentage change in total diarrheal expenditure (as a proportion of total health care spend) over 5 years assuming $5 \%$ increase in market share for racecadotril and oral rehydration solution per year.

\section{Publish your work in this journal}

ClinicoEconomics and Outcomes Research is an international, peerreviewed open-access journal focusing on health technology assessment, pharmacoeconomics and outcomes research in the areas of diagnosis, medical devices, and clinical, surgical and pharmacological intervention. The economic impact of health policy and health systems organization also constitute important areas of coverage. The manuscript management system is completely online and includes a very quick and fair peer-review system, which is all easy to use. Visit http://www.dovepress.com/testimonials.php to read real quotes from published authors. 